\title{
Characterization and Manipulation of Reproductive Cycles in the Jaguar (Panthera onca)
}

Serena A. Barnes, ${ }^{\mathrm{a}}$ J. Andrew Teare ${ }^{\mathrm{b}}$, Sheryl Staaden ${ }^{\mathrm{c}}$, Lara Metrione ${ }^{\mathrm{d}}$, and Linda M. Penfold $^{\mathrm{d}^{*}}$

${ }^{a}$ White Oak Conservation Center, 581705 White Oak Road, Yulee, FL 32097, United States.

${ }^{\mathrm{b}}$ International Species Information System, Eagan, MN 55121, United States

'Jacksonville Zoo and Gardens, 370 Zoo Parkway, Jacksonville, FL, 32218, United States

dSouth-East Zoo Alliance for Reproduction \& Conservation, 581705 White Oak Road, Yulee, FL 32097, United States

*Correspondence: Linda Penfold, South-East Zoo Alliance for Reproduction \& Conservation, 581705 White Oak Road, Yulee, FL 32097, United States. Email: Linda.Penfold@ sezarc.com. Phone: +1.904.225.3382. Fax: +1.904.225.3337 


\begin{abstract}
Basic reproductive information in female jaguars (Panthera onca) is lacking, thus longitudinal fecal samples from seven females were analyzed via enzyme immunoassay to measure estradiol and progestin metabolites throughout the year. Mean estrus length of 194 estrus periods measured hormonally was $6.5 \pm 0.3 \mathrm{~d}$, mean peak fecal estradiol concentration was $138.7 \pm 5.7 \mathrm{ng} / \mathrm{g}$; and in one female, estrus resumption occurred approximately $15 \mathrm{~d}$ post-partum. Ovulation, as indicted by sustained elevated progestin concentrations (> $20 \mathrm{~d}$ ), was successfully induced one time by treatment with exogenous hormones in one female and by physical vaginal stimulation in two females a combined total of three times. Elevated fecal progestin was observed outside exogenous stimulation on five occasions, suggesting ovulation occurred spontaneously. Mean length of physically induced and spontaneous pseudopregnancies was $24.7 \pm 4.2 \mathrm{~d}$ and $29.6 \pm 2.6$ $\mathrm{d}$, respectively, and mean length of pregnancy $(n=2)$ was $98.0 \pm 0.0 \mathrm{~d}$. Mean peak progestin concentration for spontaneous and induced pseudopregnancies, and pregnancy was $7.4 \pm 1.4 \mu \mathrm{g} / \mathrm{g}, 6.4 \pm 1.2 \mu \mathrm{g} / \mathrm{g}$, and $13.7 \pm 1.0 \mu \mathrm{g} / \mathrm{g}$, respectively. This data suggests jaguars are polyestrous and generally induced ovulators, with a moderate incidence of spontaneous ovulation. Additionally, two protocols to successfully stimulate ovarian activity in jaguars are described.
\end{abstract}

\title{
Key words: Spontaneous ovulation; ovarian stimulation; pseudopregnancy; non- invasive fecal hormone monitoring; progestins; estradiol
}




\section{Introduction}

The jaguar (Panthera onca) has declining in situ populations (Caso et al. 2008), and the captive population can provide a safeguard against extinction if the reproductive potential of ex situ individuals is maximized through natural breeding and implementation of assisted reproductive techniques (ART). ART is more efficient when ovarian activity is controlled through synchronization or stimulation prior to ART application, but a basic understanding of the jaguar's reproductive physiology is necessary to exert control of ovarian activity. Currently, little comprehensive reproductive information is available on this species compared to other large felids [e.g., Panthera leo, (Schramm et al. 1994, Umapathy et al. 2007); Acinonyx jubatus, (Howard et al. 1992, Brown et al. 1996, Howard et al. 1997, Terio et al. 2003); Panthera uncia, (Schmidt et al. 1993, Roth et al. 1997); Panthera tigris, (Crichton et al. 2003, Graham et al. 2006)].

It is essential to characterize ovarian activity in each felid species, as the presence of corpora lutea interfere with the application of ART by blunting ovarian responsiveness to ovulation-induction drugs as well as altering the endocrine environment, making it non-conducive to fertilization (Pelican et al. 2006). Though felids are generally characterized as induced ovulators (Wildt et al. 1980), in that ovulation is stimulated through mating, multiple felid species have demonstrated the ability to ovulate outside of external stimulation [e.g., Panthera leo, (Schramm et al. 1994); Neofelis nebulosa, (Brown et al. 1995); Leopardus wiedii, (Moreira et al. 2001); Otocolobus manul, (Brown et al. 2002), reviewed by (Brown 2006)]. Previous studies have suggested female jaguars 
may be induced ovulators (Sadleir 1966, Wildt et al. 1979) but lacked a sufficient sample size to draw definitive conclusions. Additionally, ovarian responsiveness to the ovulation-induction drugs varies greatly between felid species (Pelican et al. 2006), possibly inducing ovarian hyperstimulation (Stewart et al. 2012) and immune response (Swanson et al. 1996). Furthermore, no studies to date have examined ovarian stimulation and ovulation in response to exogenous chorionic gonadotropin hormone stimulation in the jaguar. As such, the ability to control ovarian activity, and potentially utilize ART, in this species is limited.

Noninvasive hormone monitoring is a successful method of collecting longitudinal endocrine data on felids, as a large percentage of steroid hormone metabolites are excreted through feces (Brown et al. 1994). This technique has been used to establish correlations between basic endocrine profiles and reproductive traits of multiple species of felid males (Brown et al. 1996, Brown et al. 1997, Morato et al. 2001, Crosier et al. 2007) and females (Brown et al. 2002, Wielebnowski et al. 2002). As such, it is a significant means of data collection to establish hormone patterns of felids. The purpose of this study was to analyze feces of female jaguars for progestin and estradiol metabolites to characterize basic reproductive events, such as estrus, pseudopregnancy and pregnancy, as well as investigate methods of ovulation induction via exogenous hormones and vaginal stimulation.

\section{Materials and Methods}

\subsection{Animals}


Adult female jaguars ( $n=7$; aged 6 - 18 years) were housed at five Association of Zoos and Aquariums institutions: Jacksonville Zoo and Gardens $(\mathrm{n}=3$; ages $6-18$, housed with physical or visual access to females and males), Zoo Miami (age 6; housed with visual access to another female and a male), Memphis Zoo (age 7; housed with another female), Oklahoma City Zoological Park (age 8; housed with physical access to a male only during estrus), and Happy Hollow Park and Zoo (age 6; housed alone) in accordance with the Species Survival Plan husbandry recommendations. All animals had exposure to natural day length and temperatures. Water was provided ad libitum at all facilities. All females were fed a commercially available feline diet in the amounts recommended by the husbandry guidelines. The study was approved by the White Oak Animal Care and Use Committee.

\subsection{Fecal sampling and processing}

All reagents were purchased from Sigma Aldrich Corporation (St. Louis, MO, USA) unless otherwise stated. Fecal samples were collected 3 - 4/wk on females for approximately 2 - 6 mo ( $\mathrm{n}=4$; controls $), 1.5$ y $(\mathrm{n}=1$; ovulation induction by exogenous hormone stimulation), and $2.5 \mathrm{y}(\mathrm{n}=2$; ovulation induction by physical vaginal stimulation). Sample collection increased to $5-7 /$ wk during periods of ovulation induction. Wet weight feces $(0.5 \mathrm{~g})$ were extracted using previously published methods for this laboratory (Metrione et al. 2008) as good correspondence in steroid concentrations was found in wet versus dried felid fecal samples (Moreira et al. 2001). Supernatant from fecal extractions were diluted with assay buffer to make 1:5 and 1:200 dilutions for the estradiol and progestin assays, respectively. Aliquots of supernatant (500 
$\mu \mathrm{L}$ ) were dried for storage and reconstituted for HPLC analysis by the addition of anhydrous alcohol (500 $\mu \mathrm{L}$; Fisher Scientific) and sonication (Branson 8510; Branson Ultrasonic Corporation, Danbury, CT; USA) for $20 \mathrm{~min}$. All fecal samples, dilutions, and supernatant aliquots were stored frozen $\left(-20^{\circ} \mathrm{C}\right)$ until analysis.

\subsection{Characterization of estrus}

Estradiol metabolites were assessed by competitive enzyme immunoassay (EIA) using an antibody produced against 1,3,5(10)-estratrien-3, 17ß-diol (Estradiol $17 \beta$ R0008; C. Munro, University of California, Davis) and estradiol:horseradish peroxidase conjugate (HRP; University of California, Davis, USA) conjugated at 6-CMO using the mixed anhydride method (Grieger et al. 1990). The cross reactivity of the $\mathrm{E}_{2}$ antibody with other hormones was Estradiol 17ß: 100\%; Estrone: 0.73\%; Estrone sulfate, 4Pregnen-3,20-dione (Progesterone), Testosterone, Cortisol, Corticosterone: $<0.01 \%$ (C. Munro, University of California, Davis). Serial dilution of pooled fecal extracts yielded parallel displacement curves compared to serial dilutions of estradiol standard. Recovery of known estradiol concentrations $(0.078 \mathrm{ng} / \mathrm{mL}-10 \mathrm{ng} / \mathrm{mL})$ added to pooled sample dilutions $(1: 5)$ was $97 \%\left(y=1.8859 x+4.699, R^{2}=0.9986\right)$. Assay sensitivity, determined as $95 \%$ binding for HRP, was $0.2 \mathrm{ng} / \mathrm{mL}$. Samples were assayed in duplicate, intra-assay coefficients of variation (CV) were $10.9 \%$ and $3.7 \%$ for high and low controls, and inter-assay variation was $7.5 \%$ and $19.8 \%$ for the high and low controls. Data are expressed in $\mathrm{ng}$ hormone metabolite mass per gram of feces $(\mathrm{ng} / \mathrm{g})$.

Estrogen metabolite analyses and behavioral assessments were used to characterize estrus. Behavioral estrus was identified by rolling, disinterest in food, vulvar 
swelling, discharge, and lordosis in animals selected for vaginal stimulation (See

Ovulation Induction). Observations of behavioral estrus coincided with fecal sample collection for endocrine analysis during six cycles, enabling comparative assessment of matched fecal hormones and behavior. Hormonal estrus was characterized as estradiol peaks greater than baseline +1.5 standard deviations (SD). Baseline concentrations in estradiol metabolite profiles were calculated using an iterative process in which values that exceeded the mean $+1.5 \mathrm{SD}$ were excluded until no values exceeded the mean +1.5 SD (Brown et al. 2001, Graham et al. 2002, North and Harder 2008). Estrus length was calculated as the last day at baseline prior to an increase in estradiol to the day prior to the next reading at baseline (Brown et al. 1994, Brown et al. 2001). The highest estradiol concentration observed during each estrous cycle was defined as the peak concentration.

\subsection{Characterization of pregnancy and pseudopregnancy}

Progestin metabolites were assessed by EIA using a monoclonal antibody produced against 4-pregnen-11-ol-3, 20-dione hemisuccinate:BSA (Progesterone CL425; C. Munro, University of California, Davis, CA, USA) and a progesterone:horseradish peroxidase conjugate (HRP; University of California, Davis, USA) conjugated at 3CMO. The cross-reactivity of this antibody has been previously published (Graham et al. 2001). Serial dilution of pooled representative fecal extracts yielded parallel displacement curves compared to serial dilutions of progestin standard. Recovery of known progestin concentrations $(0.078 \mathrm{ng} / \mathrm{mL}-10 \mathrm{ng} / \mathrm{mL})$ added to pooled fecal sample dilutions $(1: 200)$ was $107.3 \%\left(y=1.1824 x-8.624, R^{2}=0.9996\right)$. Progestin profiles were physiologically validated through observed pregnancies. Assay sensitivity, determined as $95 \%$ binding 
for HRP, was $0.08 \mathrm{ng} / \mathrm{ml}$. Samples were assayed in duplicate, intra-assay CV were 3.9\% and $4.5 \%$ for high and low controls, and inter-assay variation was $14.8 \%$ and $13.7 \%$ for the high and low controls. Data are expressed in $\mu$ g hormone metabolite mass per gram of feces $(\mu \mathrm{g} / \mathrm{g})$.

Progestin metabolite analyses were used to characterize the average length of pregnancy (last date of breeding to day of parturition) or pseudopregnancy (last date prior to sustained elevated progestin through return to baseline). Baseline concentrations in progestin profiles were calculated using the iterative process described for estradiol. Luteal concentrations were defined as those greater than baseline +2 SD (Brown et al. 1996, Graham et al. 2006, Stewart et al. 2010). Endocrine profiles with a sustained rise in progestin that reached luteal concentrations or higher for $>20$ consecutive days followed by baseline concentrations were taken as evidence of pseudopregnancy or pregnancy [modified from (Brown et al. 2001)] as ultrasound and laparoscopy were unavailable to confirm ovarian activity for every pseudopregnancy. Attenuated periods of elevated progestin, herein described as attenuated events, have been described in other species (Rawson et al. 1979, Schenken et al. 1986, Westfahl 1988) and observed in the domestic cat (Friedgood and Foster 1938) as luteinized follicles in which the oocyte is retained but the structure becomes capable of producing progestin, regresses quickly, and estrous cyclicity is unaffected (Plas-Roser et al. 1984, Hamilton et al. 1985). Currently, a thorough understanding of luteinized follicles is lacking in the Felidae taxon. However, in the domestic cat, which is a model for non-domestic felid species, the maximum in the mean duration of the domestic cat estrous cycle and the minimum time prior to regression of domestic cat corpora lutea (Paape et al. 1975) is $20 \mathrm{~d}$. Thus in this study, elevated 
progestin that was sustained $<20$ days was treated as a luteinized follicle rather than a pseudopregnancy and analyzed separately from the pseudopregnancies. The highest progestin concentration observed during each luteal phase was defined as the peak concentration.

\subsection{High-performance liquid chromatography}

A pooled sample of fecal extracts previously determined to contain high concentrations of progestin and estrogen metabolites were selected and separately concentrated via evaporation into two $12 \times 75 \mathrm{~mm}$ glass tubes (Fisher Scientific, Pittsburgh, PA, USA). Dried tubes were covered with parafilm (Pechiney Plastic Packaging, Menasha, WI, USA) and stored $\left(-20^{\circ} \mathrm{C}\right)$ until processing. The number and relative proportions of estrogen and progestin metabolites in these jaguar fecal extracts were determined using high-performance liquid chromatography (HPLC) according to previously described methods. Tritiated estradiol and estrone sulfate as well as tritiated progesterone were eluted in separate runs on the estrogen and progestin gradients as tracers for the respective metabolites. Steroid fractions $(1 \mathrm{ml})$ were separated using a reverse phase Microsorb column and collected every minute for the duration of the run. In brief, progestins were eluted using a gradient of 20-32\% acetonitrile:water (ACN) over $15 \mathrm{~min}, 50 \%$ ACN over $45 \mathrm{~min}$, and 100\% ACN over 60 min (Brown et al. 1994). Estrogens were eluted using a gradient of methanol:water (80\%:20\%) over 80 min (Dehnhard et al. 2010).

\subsection{Ovulation induction}


Three females were subjected to two methods of ovulation induction using 1) stimulation with exogenous hormones $(\mathrm{n}=1)$ or 2$)$ physical vaginal stimulation to mimic mating $(n=2)$. Control jaguars $(n=4)$ were not exogenously (hormonally or vaginally) stimulated. Two jaguars ( 1 control, 1 female exposed to vaginal stimulation) were naturally mated, and progestin profiles during pregnancy were characterized.

Exogenous hormone stimulation was induced by intramuscular administration of $600 \mathrm{IU}$ equine chorionic gonadotropin (eCG) to stimulate follicular development followed by $300 \mathrm{IU}$ human chorionic gonadotropin (hCG), administered intramuscularly $88 \mathrm{~h}$ post eCG injection to promote oocyte maturation (Roth et al. 1997). At $26 \mathrm{~h}$ post hCG injection, the female was anesthetized with telazol $(1.625 \mathrm{mg} / \mathrm{kg})$ and ketamine $(6.4$ $\mathrm{mg} / \mathrm{kg}$ ), and maintained with isoflurane (2\%) during laparoscopy (Howard et al. 1997). Ovaries were visualized using a 7-mm laparoscope (Richard Wolf Medical Instruments Corporation; Vernon Hills, IL, USA) and were manipulated using a Verres needle and grasping forceps (5-mm diameter; Richard Wolf Medical Instruments Corporation) for examination. Oocyte aspiration was conducted as part of another study (Herrick et al. 2007).

Physical vaginal stimulation was performed on female jaguars during behavioral estrus. Animals were trained with food treats to voluntarily enter a squeeze chute for stimulation. Females were stimulated by insertion of a gloved finger into the vagina and a slight circular movement employed for 30 - $60 \mathrm{sec}$. Stimulation protocols were initiated between $4 \mathrm{~d}$ prior to the start of any estrous behaviors to $2 \mathrm{~d}$ after the first signs of estrus and were conducted up to 5 times during the period that estrus behaviors were observed. 


\subsection{Statistical analysis}

Data was analyzed using SigmaStat 3.0 to establish if any statistical differences existed in mean fecal progestin or estradiol patterns between attenuated events, spontaneous pseudopregnancies, and induced pseudopregnancies observed in three females that were exogenously stimulated. Mean progestin duration and peak concentrations were analyzed via respective repeated measures One Way Analysis of Variance (rmANOVA) to determine if any significant differences $(p<0.05)$ were present in progestin patterns during luteal events. Mean estradiol duration and peak concentrations were similarly analyzed via rmANOVA to determine if any significant differences $(p<0.05)$ were present in estradiol patterns prior to spontaneous ovulations, induced ovulations, or attenuated events. An all-pairwise multiple comparisons test (Holm-Sidak method) was used to determine which data were statistically different when significant differences were found in respective rmANOVAs. Events associated with the exogenous hormone stimulation, specifically estrus length, peak estradiol concentration, luteal concentration, or duration, were not included in any statistical analyses due to small sample size $(\mathrm{n}=1)$ of this group.

To characterize the effectiveness of the physical vaginal stimulation technique, Spearman correlation was used to identify relationships between 1) the frequency of stimulation during estrus and the duration of behavioral estrus and 2) the frequency of stimulation during estrus and the number of days from the last day of estrus to the rise in progestins. In addition, data were examined to determine if the number of days from the first day of physical vaginal stimulation during estrus to the rise in progestins decreased 
over the course of the study, as this might indicate a "trained" response by the jaguars to ovulate upon entering the squeeze chute and commencing physical stimulation.

\section{Results}

\subsection{Characterization of estrus activity}

Antibodies used for steroid hormone metabolite analysis in this study were pharmacologically and physiologically validated, observed as corresponding increases in estradiol fecal concentrations during exogenous hormone stimulation as well as peaks in estradiol that corresponded to fertile breeding. Estrus activity, as determined by estrogen metabolite profiles, was detected in all seven females (Fig. 1 - 5). Exogenous hormone stimulation resulted in an increase in estradiol concentrations approximately $5 \times$ above baseline (denoted by ${ }^{\diamond}$; Fig. 1; Table 1), lasting $13 \mathrm{~d}(\mathrm{n}=1)$. Estrus length (excluding exogenous hormone stimulation) for all observed hormonal estrus (194 occurrences) was $6.5 \pm 0.3 \mathrm{~d}$ with a mean estradiol peak of $138.7 \pm 5.7 \mathrm{ng} / \mathrm{g}$. On average, peak estradiol concentrations increased approximately $2.1 \times$ above baseline concentrations during hormonal estrus. Mean estrus length prior to physically induced ovulation $(\mathrm{n}=3$

ovulations), as determined by a rise in progestins to luteal concentrations $>20 \mathrm{~d}$, was 8.3 $\pm 5.8 \mathrm{~d}$ and had a mean estradiol peak of $150.4 \pm 35.2 \mathrm{ng} / \mathrm{g}$. The length of estrus prior to spontaneous ovulation ( $\mathrm{n}=5$ ovulations) was $10.4 \pm 2.5 \mathrm{~d}$ and had a mean estradiol peak of $206.0 \pm 74.1 \mathrm{ng} / \mathrm{g}$. Mean estrus length did not significantly differ $(p>0.05)$ between induced and spontaneous sustained elevations in progestin concentrations. Mean estrus length and peak concentration prior to all pseudopregnancies, specifically spontaneous and induced, are listed in Table 1. Mean estrus length prior to attenuated events, as 
determined by a rise in progestin to luteal concentrations $<20 \mathrm{~d}$, was $16.0 \pm 4.5 \mathrm{~d}(\mathrm{n}=13$ occurrences) and had a mean estradiol peak of $198.4 \pm 38.1 \mathrm{ng} / \mathrm{g}$. Post-partum estrus resumption was noted $15 \mathrm{~d}$ after parturition in one female.

Behavioral estrus length ( $\mathrm{n}=8$ estrus events) was $7.8 \pm 0.7 \mathrm{~d}$, with a range of 4 to $11 \mathrm{~d}$ for the two females in the physical stimulation experiment. Observed behavioral estrus events corresponded with six of the 13 observed hormonal estrus events detected with EIA during the observation period. For these six periods of estrus, the length of behavioral estrus appeared slightly longer than the length of hormonal estrus $(4.0 \pm 1.4$ d). There was no correlation $(p>0.05)$ between the frequency of stimulation during estrus and the number of days from the last day of behavioral estrus to the rise in progestins. The number of days from the first day of physical vaginal stimulation during estrus to the rise in progestins did not decrease over the course of the study (chronologically: 7, 9, 9, 10, 5, and 9 days). However, more frequent stimulation was correlated $(p=0.05)$ with a shorter behavioral estrus.

In response to exogenous hormone stimulation, ovarian activity in the form of $8 \times$ 2 - $6 \mathrm{~mm}$ follicles was confirmed visually on the right ovary and $1 \times 2-6 \mathrm{~mm}$ follicle was observed on the left ovary. One 10 - $12 \mathrm{~mm}$ cyst was also observed on the left ovary. No corpora lutea were observed on either ovary. Two of the nine oocytes collected from the follicles had dark nuclei, expanded cumulus cells and intact corona radiate, and thus were considered high-quality oocytes.

\subsection{Characterization of pseudopregnancy}


Antibodies used for progestin hormone metabolite analysis in this study were pharmacologically and physiologically validated, observed as corresponding increases in progestin fecal concentrations after exogenous hormone stimulation and pregnancy. Progestin concentrations as detected by EIA increased after natural mating or oocyte aspiration and returned to baseline after parturition or the presumed end of a nonpregnant luteal phase. Ovulation, defined here by sustained elevated progestin concentrations $>20 \mathrm{~d}$, was successfully induced by treatment with exogenous hormones (Fig. 1) and physical vaginal stimulation (Fig. 2 - 3), but was not observed in any females housed in the absence of males. In response to exogenous hormone stimulation, elevated progestin and assumed pseudopregnancy was observed in a 17 year old female for $207 \mathrm{~d}$ (Fig 1; Table 1) which was much longer than all other pseudopregnancy lengths. Pseudopregnancy was induced via physical vaginal stimulation one time out of 19 stimulation trials in one female (5\%, Fig. 2) and two times out of five stimulation trials in a second female (40\%, Fig. 3). Mean duration and peak progestin concentration for induced pseudopregnancy (range: $20-33 \mathrm{~d}$ ) are listed in Table 2 .

Spontaneous ovulation was detected a total of five times during the study period in the females that were housed in the presence of two males. These females were also those that had previously experienced vaginal or hormonal stimulation female (Fig. 1 3). Spontaneous ovulation was not detected in the four non-pregnant control females that were maintained in the absence of males (Fig. 5). Mean duration and peak progestin concentration for spontaneous pseudopregnancy (range: $21-37 \mathrm{~d}$ ) are listed in Table 2 and were similar $(p>0.05)$ in length and peak concentration compared to ovulations that occurred as a result of physical vaginal stimulation. Mean progestin duration and peak 
concentration for all pseudopregnancies, specifically spontaneous and induced, are listed in Table 1. Progestin duration ( $8.5 \pm 1.2 \mathrm{~d}, 2$ - $15 \mathrm{~d}$ range) during attenuated events was lower $(p<0.05)$ than those of spontaneous and induced ovulations; however, peak progestin concentration $(4.5 \pm 1.0 \mu \mathrm{g} / \mathrm{g})$ during attenuated events was not different $(p>$ 0.05) from those of pseudopregnancies.

\subsection{Characterization of Pregnancy}

One of the four control females (Fig. 4) and one stimulated female (Fig. 3) displayed sustained elevated progestins in the form of pregnancy following natural mating. Length of pregnancy for both cats was $98.0 \mathrm{~d}$ and concluded in the births of healthy, singleton cubs.

\subsection{High-performance liquid chromatography}

HPLC for progestins detected polar, conjugated metabolite peaks at fractions 1 - 7 and 7 17, while a nonpolar metabolite was measured at fractions $73-77$. No fraction was eluted with the progesterone tracer (fractions 65 -69) similar to trends in other felids (Brown et al. 1994), but a peak was observed seven minutes after the tracer (Fig 6). For estrogens, multiple immunoreactive peaks were detected by HPLC, with a notable conjugated peak eluting with the estradiol tracer (fraction 59-64) and an unconjugated peak eluting two minutes after the tracer (Fig 7).

\section{Discussion}


The results of this study characterize the reproductive endocrinology of the female jaguar, with attention to estrus, pseudopregnancy and pregnancy. Evidence of both induced and spontaneous ovulation was observed in this species, with pseudopregnancies observed in both the presence and absence of exogenous stimulation. The mean duration of estrus determined in this study was consistent with previous reports for the jaguar (Sadleir 1966, Wildt et al. 1979) and those of other felid species (Verhage et al. 1976, Schmidt et al. 1988, Brown et al. 1995, Graham et al. 2006, Dorsser et al. 2007, Umapathy et al. 2007, Goritz et al. 2009, Herrick et al. 2010). Fecal estrogen concentrations increased 2-fold above baseline during estrus compared to 3 -fold in leopard cat, cheetah, clouded leopard, and snow leopard (Brown et al., 1994). Similarly, a high amount of individual variation in estrus length was observed in this study which has also previously been observed in the jaguar (Sadleir 1966, Wildt et al. 1979) and other felid species (Brown et al. 1996, Graham et al. 2006, Herrick et al. 2010). In addition to the variation between individuals, the duration of behavioral estrus was longer than that of hormonal estrus, and estrus behaviors were not necessarily observed during each estrous cycle. Hormonal estrus occurring in the absence of behavioral cues also has been noted in the domestic cat (Wildt et al. 1978). These findings suggest hormone monitoring might provide a more reliable indicator of estrus than observations of estrous behavior.

Previous observations in this species suggested the jaguar is primarily an induced ovulator (Wildt et al. 1979). However in this study, sustained increases in progestin were observed in three of the seven females outside of any exogenous stimulation, whether physically or hormonally, similar in peak concentration and duration to those after exogenous stimulation. All three females were housed with exposure to two males, but 
incidentally were housed at the same institution. As spontaneous ovulation has been observed to various degrees in many felid species (Schramm et al. 1994, Brown et al. 1995, Brown et al. 1996, Moreira et al. 2001, Terio et al. 2003, Brown 2006), it is highly probable this species is capable of spontaneous ovulation, indicated by the luteal phases outside of exogenous stimulation. Attenuated events $(<20 \mathrm{~d})$ were more likely the result of luteinized follicles, similar to observations in hyperstimulated domestic cats (Friedgood and Foster 1938, Swanson et al. 1996), guinea pigs (Westfahl 1988, Westfahl 1993), rhesus monkeys (Schenken et al. 1986), humans (Hamilton et al. 1985, Xu et al. 2011), and rats (Plas-Roser et al. 1984) rather than from active, fully formed corpora lutea. These findings also suggest that the hypothalamic-pituitary-gonadal axis of jaguars naturally might be variably responsive to external stimuli, similar to observations in other felids (Brown and Wildt 1997).

This study has also demonstrated that ovulation can be induced by simple physical stimulation in trained females, in this case using behavioral estrus as an indicator for reproductive receptivity. The option of a manual protocol in which the animal is a willing participant is particularly appealing because it is inexpensive, can be accomplished by appropriately trained keeper staff without veterinary involvement, and can be repeated frequently without any negative corollaries. As the number of days from the first day of physical vaginal stimulation to the rise in progestins did not decrease over the course of the study, it did not appear that the females were "trained" to ovulate by the cues experienced during the manual protocol, but rather ovulation was a response to sufficient physical stimuli. More frequent stimulation appeared to result in a shorter behavioral estrus as might be expected, but did not appear to affect latency to the rise in 
progestins after behavioral estrus. The success rate of this protocol was variable between individuals, and so the ability to reliably induce ovulation with this method still requires optimization. Using hormone monitoring to identify estrus rather than relying on behavioral cues might be advantageous.

This study is believed to be the first to induce hormonal evidence of ovarian activity with eCG and hCG in this species. Previous stimulation protocols have successfully used hCG to induce ovulation during natural estrus, assumed by the presence of corpora lutea, in the jaguar (Wildt et al. 1979). In the present study, the collection of high quality oocytes from pre-ovulatory follicles suggests this two-step gonadotropin protocol also successfully stimulated follicular development, and potentially oocyte maturation. Despite extensive investigation of exogenous gonadotropin stimulation in the domestic cat and other endangered felids (Wildt et al. 1981, Howard et al. 1992, Pelican et al. 2006), limited research has been performed on jaguars. It is important to systematically develop stimulation protocols on a species-specific basis, as improper regimes can trigger immune responses (Swanson et al. 1995) or induce abnormal uterine environments not conducive to implantation (Swanson et al. 1997, Brown 2006). Similarly after chorionic gonadotropin stimulation, the older female (17 years) had a $5 \times$ increase in estradiol concentration as well as a much longer pseudopregnancy length compared to all other reproductive events observed in this study, possibly indicative of over stimulation from the hormone regime or advanced age. As such, the effects of this stimulation protocol on the uterine environment and long term reproductive health in the jaguar requires further examination. Stimulation protocols using porcine gonadotropins have also been successfully used on Panthera species, including the jaguar (Morato et al. 
2002, Crichton et al. 2003), likely due to the high compatibility of porcine gonadotropins with the feline FSH receptor which is highly conserved within the felid taxon (Neubauer et al. 2006). Thus, while eCG and hCG have the potential to produce high quality oocytes, it would be beneficial to further research the effects of gonadotropin stimulation protocols on oocyte maturation as well as attempt to reduce the dramatic effects following this hormone regime in the jaguar.

Mean gestation length for the jaguar in this study was similar to those of the other members of the Panthera genus (91-110 d) (Dresser et al. 1982, Schmidt et al. 1993, Graham et al. 1995, Graham et al. 2006). Additionally, pseudopregnancy length for the jaguars in this study was $\sim 30$ days for spontaneous ovulation and $\sim 25$ days for induced ovulation, similar to observations in other Panthera species [tiger, $35 \mathrm{~d}$ (Graham et al. 2006); lion, 55 d (Briggs et al. 1990); leopard, 39 d (de Haas van Dorsser et al. 2007)]. However, estradiol and progestin concentrations during reproductive events in these jaguars were much lower than what has been previously reported in other felid species. Dissimilar extraction methods (Brown and Wildt 1997), specifically the use of wet weight feces versus the use of desiccated feces, and immunoassays, i.e. EIA versus radio immunoassay, used to monitor fecal hormones (Van Weeme and Schuurs 1971) may have contributed to the large disparity between the hormonal concentrations found in this species compared to those of other felids. HPLC analysis did find that, similar to other felids, progestins were excreted as metabolites, and progestin fractions eluted at similar time points to those in other species, suggesting the metabolites contain a similar polarity (Brown et al. 1994). Nonetheless, comparisons between the actual progestin concentrations in this and previous studies should be done with caution. 
This study has enabled further accumulation of basic reproductive knowledge on the female jaguar, which can improve ex situ breeding. Additionally, fecal hormone monitoring can be used in combination with ART to improve the timing of reproductive procedures in this species, as in other felid species (Brown et al. 2001). Consequently, the results from this study could significantly contribute to jaguar conservation.

\section{Conclusions}

1.) Estradiol $17 \beta$ R0008 and Progesterone CL425 antibodies can be used to monitor reproductive activity in female jaguar feces.

2.) Fecal hormone analysis indicates female jaguars are polyestrual induced ovulators, with the potential to spontaneously ovulate.

3.) Pseudopregnancy length (27.7 days) is similar to that of other Panthera species.

4.) Two methods of exogenous ovulation induction, one physical and one hormonal, were validated and could have significant implications for artificial insemination procedures in the future.

\section{Acknowledgements}


The authors would like to thank the staffs of Jacksonville Zoo and Gardens, Zoo Miami, Memphis Zoo, Oklahoma City Zoological Park, and Happy Hollow Zoo for their collaboration with this project, Dr. Janine Brown at Smithsonian Conservation Biological Institute for HPLC analysis, and Dr. William Swanson for his assistance with laparoscopy. We also thank the reviewers and editors for comments and suggestions that significantly enhanced and clarified this manuscript.

\section{References}

Briggs, M. B., Fithian, C. L., Starkey, P. R., Richards, R. E., Schramm, R. D., Reeves, J. J. 1990. Endocrine profiles in estrus, pregnant and pseudopregnant African lions (Panthera leo) throughout the year. Annual Proceedings of the American Association of Zoo Veterinarians: 279-281.

Brown, J. L. 2006. Comparative endocrinology of domestic and nondomestic felids. Theriogenology 66(1): 25-36.

Brown, J. L., Graham, L. H., Wielebnowski, N., Swanson, W. F., Wildt, D. E., Howard, J. G. 2001. Understanding the basic reproductive biology of wild felids by monitoring of faecal steroids. J Reprod Fertil Suppl 57: 71-82.

Brown, J. L., Graham, L. H., Wu, J. M., Collins, D., Swanson, W. F. 2002. Reproductive endocrine responses to photoperiod and exogenous gonadotropins in the Pallas' cat (Otocolobus manul). Zoo Biol 21(4): 347-364.

Brown, J. L., Swanson, W. F., Graham, L. H. 1997. Reproductive patterns in male and female Pallas' cats determined by fecal steroid metabolite analysis. Biol Reprod 56: 8888.

Brown, J. L., Terio, K. A., Graham, L. H. 1996. Fecal androgen metabolite analysis for non invasive monitoring of testicular steroidogenic activity in felids. Zoo Biol 15(4): 425-434. 
Brown, J. L., Wasser, S. K., Wildt, D. E., Graham, L. H. 1994. Comparative aspects of steroid hormone metabolism and ovarian activity in felids, measured noninvasively in feces. Biol Reprod 51(4): 776-786.

Brown, J. L., Wildt, D. E. 1997. Assessing reproductive status in wild felids by noninvasive faecal steroid monitoring. Int Zoo Yb 35(0): 173-191.

Brown, J. L., Wildt, D. E., Graham, L. H., Byers, A. P., Collins, L., Barrett, S., Howard, J. G. 1995. Natural versus chorionic gonadotropin-induced ovarian responses in the clouded leopard (Neofelis nebulosa) assessed by fecal steriod analysis. Biol Reprod 53(1): 93-102.

Brown, J. L., Wildt, D. E., Wielebnowski, N., Goodrowe, K. L., Graham, L. H., Wells, S., Howard, J. G. 1996. Reproductive activity in captive female cheetahs (Acinoyx jubatus) assessed by faecal steroids. J Reprod Fertil 106(2): 337-346.

Caso, A., Lopez-Gonzalez, C., Payan, E., Eizirik, E., de Oliveira, T., Leite-Pitman, R., Kelly, M., Valderrama, C. 2008. Panthera onca.

Crichton, E. G., Bedows, E., Miller-Lindholm, A. K., Baldwin, D. M., Armstrong, D. L., Graham, L. H., Ford, J. J., Gjorret, J. O., Hyttel, P., Pope, C. E., Vajta, G., Loskutoff, N. M. 2003. Efficacy of porcine gonadotropins for repeated stimulation of ovarian activity for oocyte retrieval and in vitro embryo production and cryopreservation in Siberian tigers (Panthera tigris altaica). Biol Reprod 68(1): 105-113.

Crosier, A. E., Marker, L., Howard, J., Pukazhenthi, B. S., Henghali, J. N., Wildt, D. E. 2007. Ejaculate traits in the Namibian cheetah (Acinonyx jubatus): influence of age, season and captivity. Reprod Fertil Dev 19(2): 370-382.

de Haas van Dorsser, F. J., Green, D. I., Holt, W. V., Pickard, A. R. 2007. Ovarian activity in Arabian leopards (Panthera pardus nimr): sexual behaviour and faecal steroid monitoring during the follicular cycle, mating and pregnancy. Reprod Fertil Dev 19(7): $822-830$.

Dehnhard, M., Fanson, K., Frank, A., Naidenko, S. V., Vargas, A., Jewgenow, K. 2010. Comparative metabolism of gestagens and estrogens in the four lynx species, the Eurasian (Lynx lynx), the Iberian (L. pardinus), the Canada lynx (L. canadensis) and the bobcat (L. rufus). Gen Comp Endocrinol 167(2): 287-296. 
Dorsser, F. J. d. H. v., Green, D. I., Holt, W. V., Pickard, A. R. 2007. Ovarian activity in Arabian leopards (Panthera pardus nimr): sexual behaviour and faecal steroid monitoring during the follicular cycle, mating and pregnancy. Reprod Fertil Dev 19(7): 822-830.

Dresser, B. L., Kramer, L., Reece, K., Russell, P. T. 1982. Induction of ovulation and successful artificial insemination in a Persian leopard (Panthera pardus saxicolor). Zoo Biol 1(1): 55-57.

Friedgood, H. B., Foster, M. A. 1938. The experimental production of ovulation, luteinization and cysts of the corpus luteum in adrenalectomized anestrous cats. American Journal of Physiology 123: 237-242.

Goritz, F., Dehnhard, M., Hildebrandt, T. B., Naidenko, S. V., Vargas, A., Martinez, F., Lopez-Bao, J. V., Palomares, F., Jewgenow, K. 2009. Non Cat-Like Ovarian Cycle in the Eurasian and the Iberian Lynx - Ultrasonographical and Endocrinological Analysis. Reprod Domest Anim 44: 87-91.

Graham, L., Schwarzenberger, F., Mostl, E., Galama, W., Savage, A. 2001. A versatile enzyme immunoassay for the determination of progestogens in feces and serum. Zoo Biol 20(3): 227-236.

Graham, L. H., Byers, A. P., Armstrong, D. L., Loskutoff, N. M., Swanson, W. F., Wildt, D. E., Brown, J. L. 2006. Natural and gonadotropin-induced ovarian activity in tigers (Panthera tigris) assessed by fecal steroid analyses. Gen Comp Endocrinol 147(3): 362370.

Graham, L. H., Goodrowe, K. L., Raeside, J. I., Liptrap, R. M. 1995. Non-invasive monitoring of ovarian function in several felid species by measurement of fecal estradiol17-beta and progestins. Zoo Biol 14(3): 223-237.

Graham, L. H., Reid, K., Webster, T., Richards, M., Joseph, S. 2002. Endocrine patterns associated with reproduction in the Nile hippopotamus (Hippopotamus amphibius) as assessed by fecal progestagen analysis. Gen Comp Endocrinol 128(1): 74-81.

Grieger, D. M., Scarborough, R., deAvila, D. M., Johnson, H. E., Reeves, J. J. 1990. Active immunization of beef heifers against luteinizing hormone: III. Evaluation of dose and longevity. J Anim Sci 68(11): 3755-3764. 
Hamilton, C. J., Wetzels, L. C., Evers, J. L., Hoogland, H. J., Muijtjens, A., de Haan, J. 1985. Follicle growth curves and hormonal patterns in patients with the luteinized unruptured follicle syndrome. Fertil Steril 43(4): 541-548.

Herrick, J. R., Bond, J. B., Campbell, M., Levens, G., Moore, T., Benson, K., D'Agostino, J., West, G., Okeson, D. M., Coke, R., Portacio, S. C., Leiske, K., Kreider, C., Polumbo, P. J., Swanson, W. F. 2010. Fecal endocrine profiles and ejaculate traits in black-footed cats (Felis nigripes) and sand cats (Felis margarita). Gen Comp Endocrinol 165(2): 204-214.

Herrick, J. R., Bond, J. B., Magarey, G. A., Bateman, H. L., Krisher, R. L., Dunford, S. A., Swanson, W. F. 2007. Toward a feline-optimized culture medium: Impact of ions, carbohydrates, essential amino acids, vitamins, and serum on development and metabolism of in vitro fertilization-derived feline embryos relative to embryos grown in vivo. Biol Reprod 76(5): 858-870.

Howard, J. G., Donoghue, A. M., Barone, M. A., Goodrowe, K. L., Blumer, E. S., Snodgrass, K., Starnes, D., Tucker, M., Bush, M., Wildt, D. E. 1992. Successful induction of ovarian activity and laparoscopic intrauterine artificial insemination in the cheetah (Acinonyx jubatus). J Zoo Wildlife Med 23(3): 288-300.

Howard, J. G., Roth, T. L., Byers, A. P., Swanson, W. F., Wildt, D. E. 1997. Sensitivity to exogenous gonadotropins for ovulation induction and laparoscopic artificial insemination in the cheetah and clouded leopard. Biol Reprod 56(4): 1059-1068.

Metrione, L. C., Norton, T. M., Beetem, D., Penfold, L. M. 2008. Seasonal reproductive characteristics of female and male Jackson's hartebeest (Alcelaphus buselaphus jacksoni). Theriogenology 70(6): 871-879.

Morato, R. G., Conforti, V. A., Azevedo, F. C., Jacomo, A. T., Silveira, L., Sana, D., Nunes, A. L., Guimaraes, M. A., Barnabe, R. C. 2001. Comparative analyses of semen and endocrine characteristics of free-living versus captive jaguars (Panthera onca). Reproduction 122(5): 745-751.

Morato, R. G., Crichton, E., Paz, R. C. R., Zuge, R. M., Moura, C. A., Nunes, A. L. V., Teixeira, R. H., Guimaraes, M. A. B. V., Barnabe, V. H., Barnabe, R. C., Armstrong, D., Loskutoff, N. 2002. Ovarian stimulation, oocyte recovery and in vitro fertilization in the jaguar (Panthera onca). Revista Brasileira de Reproducao Animal 26(4): 317-324.

Moreira, N., Monteiro-Filho, E. L., Moraes, W., Swanson, W. F., Graham, L. H., Pasquali, O. L., Gomes, M. L., Morais, R. N., Wildt, D. E., Brown, J. L. 2001. 
Reproductive steroid hormones and ovarian activity in felids of the Leopardus genus. Zoo Biol 20(2): 103-116.

Neubauer, K., Jewgenow, K., Fickel, J. 2006. Follicle-stimulating hormone receptor in felids: intra- and interspecies variation. Theriogenology 66(6-7): 1737-1742.

North, L. A., Harder, J. D. 2008. Characterization of the estrous cycle and assessment of reproductive status in Matschie's tree kangaroo (Dendrolagus matschiei) with fecal progestin profiles. Gen Comp Endocrinol 156(1): 173-180.

Paape, S. R., Shille, V. M., Seto, H., Stabenfeldt, G. H. 1975. Luteal activity in the pseudopregnant cat. Biol Reprod 13(4): 470-474.

Pelican, K. M., Wildt, D. E., Pukazhenthi, B., Howard, J. 2006. Ovarian control for assisted reproduction in the domestic cat and wild felids. Theriogenology 66(1): 37-48.

Plas-Roser, S., Kauffmann, M. T., Aron, C. 1984. Progesterone secretion by luteinized unruptured follicles in mature female rats. J Steroid Biochem 20(1): 441-444.

Rawson, J. M., Galey, C. I., Weinberg, L. C., Hodgson, B. J. 1979. Effects of gonadotropins on follicular development, ovulation, and atresia in the mature guinea pig. Horm Res 10(1): 25-36.

Roth, T. L., Armstrong, D. L., Barrie, M. T., Wildt, D. E. 1997. Seasonal effects on ovarian responsiveness to exogenous gonadotrophins and successful artificial insemination in the snow leopard (Uncia uncia). Reprod Fertil Dev 9(3): 285-295.

Sadleir, R. M. F. S. 1966. Notes on reproduction in the larger Felidae. Int Zoo Yb 6: 184187.

Schenken, R. S., Werlin, L. B., Williams, R. F., Prihoda, T. J., Hodgen, G. D. 1986. Histologic and hormonal documentation of the luteinized unruptured follicle syndrome. Am J Obstet Gynecol 154(4): 839-847.

Schmidt, A. M., Hess, D. L., Schmidt, M. J., Lewis, C. R. 1993. Serum concentrations of estradiol and progesterone and frequency of sexual behavior during the normal estrous cycle in the snow leopard (Panthera unica). J Reprod Fertil 98(1): 91-95. 
Schmidt, A. M., Hess, D. L., Schmidt, M. J., Smith, R. C., Lewis, C. R. 1988. Serum concentrations of oestradiol and progesterone, and sexual behaviour during the normal oestrous cycle in the leopard (Panthera pardus). J Reprod Fertil 82(1): 43-49.

Schramm, R. D., Briggs, M. B., Reeves, J. 1994. Spontaneous and induced ovulation in the lion (Panthera leo). Zoo Biol 13(4): 301-307.

Stewart, R. A., Pelican, K. M., Brown, J. L., Wildt, D. E., Ottinger, M. A., Howard, J. G. 2010. Oral progestin induces rapid, reversible suppression of ovarian activity in the cat. Gen Comp Endocrinol 166(2): 409-416.

Stewart, R. A., Pelican, K. M., Crosier, A. E., Pukazhenthi, B. S., Wildt, D. E., Ottinger, M. A., Howard, J. 2012. Oral progestin priming increases ovarian sensitivity to gonadotropin stimulation and improves luteal function in the cat. Biol Reprod 87(6): 137.

Swanson, W. F., Graham, K., Horohov, D. W., Thompson, D. L., Jr., Godke, R. A. 1996. Ancillary follicle and secondary corpora lutea formation following exogenous gonadotropin treatment in the domestic cat and effect of passive transfer of gonadotropinneutralizing antisera. Theriogenology 45(3): 561-572.

Swanson, W. F., Horohov, D. W., Godke, R. A. 1995. Production of exogenous gonadotrophin-neutralizing immunoglobulins in cats after repeated eCG-hCG treatment and relevance for assisted reproduction in felids. J Reprod Fertil 105(1): 35-41.

Swanson, W. F., Roth, T. L., Graham, K., Horohov, D. W., Godke, R. A. 1996. Kinetics of the humoral immune response to multiple treatments with exogenous gonadotropins and relation to ovarian responsiveness in domestic cats. Am J Vet Res 57(3): 302-307.

Swanson, W. F., Wolfe, B. A., Brown, J. L., Martin-Jimenez, T., Riviere, J. E., Roth, T. L., Wildt, D. E. 1997. Pharmacokinetics and ovarian-stimulatory effects of equine and human chorionic gonadotropins administered singly and in combination in the domestic cat. Biol Reprod 57(2): 295-302.

Terio, K. A., Marker, L., Overstrom, E. W., Brown, J. L. 2003. Analysis of ovarian and adrenal activity in Namibian cheetahs. S Afr J Wildl Res 33(2): 71-78.

Umapathy, G., Sontakke, S. D., Srinivasu, K., Kiran, T., Kholkute, S. D., Shivaji, S. 2007. Estrus behavior and fecal steroid profiles in the Asiatic lion (Panthera leo persica) during natural and. gonadotropin-induced estrus. Animal Reproduction Science 101(3-4): 313-325. 
Van Weeme, B. K., Schuurs, A. H. W. 1971. Immunoassay using antigen enzyme conjugates. Febs Letters 15(3): 232-236.

Verhage, H. G., Beamer, N. B., Brenner, R. M. 1976. Plasma levels of estradiol and progesterone in cat during poly-estrus, pregnancy and pseudopregnancy. Biol Reprod 14(5): 579-585.

Westfahl, P. K. 1988. Circulating sex steroids after induction of luteinized unruptured follicles in adult guinea pigs. Steroids 51: 101-114.

Westfahl, P. K. 1993. Comparison of luteinized unruptured follicles and corpora lutea: steroid hormone production and response to luteolytic and luteotropic agents. Biol Reprod 48(4): 807-814.

Wielebnowski, N. C., Ziegler, K., Wildt, D. E., Lukas, J., Brown, J. L. 2002. Impact of social management on reproductive, adrenal and behavioural activity in the cheetah (Acinonyx jubatus). Anim Conserv 5: 291-301.

Wildt, D. E., Guthrie, S. C., Seager, S. W. 1978. Ovarian and behavioral cyclicity of the laboratory maintained cat. Horm Behav 10(3): 251-257.

Wildt, D. E., Platz, C. C., Chakraborty, P. K., Seager, S. W. 1979. Oestrous and ovarian activity in a female jaguar (Panthera onca). J Reprod Fertil 56(2): 555-558.

Wildt, D. E., Platz, C. C., Seager, S. W., Bush, M. 1981. Induction of ovarian activity in the cheetah (Acinonyx jubatus). Biol Reprod 24(1): 217-222.

Wildt, D. E., Seager, S. W., Chakraborty, P. K. 1980. Effect of copulatory stimuli on incidence of ovulation and on serum luteinizing hormone in the cat. Endocrinology 107(4): 1212-1217.

Xu, W., Yang, J., Jiang, L., Hu, J. 2011. Impact of luteinized unruptured follicles on endometrial receptivity. J Huazhong Univ Sci Technolog Med Sci 31(2): 181-184. 
Table 1. Duration of elevated progestin and hormonal estrus, and peak fecal hormone metabolites in female jaguars under different ovulation induction regimes.

\begin{tabular}{|c|c|c|c|c|}
\hline Animals & $\begin{array}{l}\text { Mean Length } \\
\text { of Elevated } \\
\text { Progestin (d) }\end{array}$ & $\begin{array}{l}\text { Peak Progestin } \\
\text { Concentration } \\
(\mu \mathrm{g} / \mathrm{g} \text { feces })\end{array}$ & $\begin{array}{l}\text { Length of } \\
\text { Hormonal Estrus } \\
\text { (d) }\end{array}$ & $\begin{array}{c}\text { Peak Estradiol } \\
\text { Concentration } \\
\text { (ng/g feces) }\end{array}$ \\
\hline $\begin{array}{l}\text { Exogenous } \\
\text { Hormone Stimulated }\end{array}$ & 207. 0 & 4.2 & 13.0 & 338.6 \\
\hline Physically Stimulated $^{\circ}$ & $27.7 \pm 2.3$ & $7.1 \pm 0.9$ & $9.6 \pm 2.5$ & $185.2 \pm 46.9$ \\
\hline Attenuated Event ${ }^{\psi}$ & $8.5 \pm 1.2$ & $4.5 \pm 1.0$ & $16.0 \pm 4.5$ & $198.4 \pm 38.1$ \\
\hline Natural Breeding $\dagger$ & $98.0 \pm 0.0$ & $13.7 \pm 1.0$ & $21.0(n=1)$ & $518.0(n=1)$ \\
\hline Control & $\mathrm{N} / \mathrm{A}$ & $\mathrm{N} / \mathrm{A}$ & $5.5 \pm 0.4$ & $136.4 \pm 14.0$ \\
\hline
\end{tabular}

$\dagger$ Pregnancy. Estrous cycle of natural breeding was unavailable for one female. ${ }^{\circ}$ Result includes luteal phases from both spontaneous $(n=5$ occurrences $)$ and induced ( $n=3$ occurrences) ovulations. ${ }^{\psi}$ Attenuated events ( $n=13$ occurrences) were $2-15$ d periods of elevated progestin followed by baseline concentrations, and were observed in females that had experienced one of two ovulation induction methods as well as were housed with exposure to males. 
Table 2. Summary of sustained, elevated progestin concentrations among spontaneous and induced pseudopregnancies, and attenuated events.

\begin{tabular}{clll}
\hline & Spontaneous & $\begin{array}{l}\text { Physical } \\
\text { Stimulation }\end{array}$ & $\begin{array}{l}\text { Attenuated } \\
\text { Event }\end{array}$ \\
\hline Length of Pseudopregnancy $(\mathrm{d})$ & $29.6 \pm 2.6(\mathrm{n}=5)$ & $24.7 \pm 4.2(\mathrm{n}=3)$ & $8.5 \pm 1.2(\mathrm{n}=13)$ \\
Peak Progestin $(\boldsymbol{\mu g} / \mathbf{g}$ feces $)$ & $7.4 \pm 1.4$ & $6.4 \pm 1.2$ & $4.5 \pm 1.0$ \\
\hline${ }^{\psi}$ Attenuated events were $2-15$ d elevations in progestin followed by baseline concentrations. $\mathrm{N}=$ refers to \\
number of occurrences in three animals over a period of two years.
\end{tabular}


Figure Captions:

Fig. 1. Progestin and estradiol hormone profiles from an exogenous hormone-stimulated female jaguar. * denotes spontaneous ovulation, $\diamond$ denotes exogenous hormone induced ovulation. ${ }^{\psi}$ denotes attenuated periods of elevated progestin $(<20 \mathrm{~d})$.

Fig. 2. Progestin and estradiol profiles following repeated induced ovulation after physical stimulation, and spontaneous ovulation in a female jaguar. * denotes spontaneous ovulation, ${ }^{\circ}$ denotes induced ovulation, ${ }^{\psi}$ denotes attenuated periods of elevated progestin $(<20 \mathrm{~d})$.

Fig. 3. Induced and spontaneous ovulation as well as pregnancy following mating in a jaguar. ${ }^{*}$ denotes spontaneous ovulation, ${ }^{\circ}$ denotes induced ovulation, ${ }^{\psi}$ denotes attenuated periods of elevated progestin $(<20 \mathrm{~d})$.

Fig. 4. Pregnancy profile of a naturally mated female jaguar.

Fig. 5. Representative progestin and estradiol hormone profiles of an unstimulated (control) female jaguar housed without a male.

Fig. 6. Fraction elution profile for progestin HPLC analysis. The peak in the tritiated tracer profile represents progesterone (H3-P4).

Fig. 7. Fraction elution profile for estradiol HPLC analysis. Peaks in the tritiated tracer profile represent estrone sulfate (H3-E1S) and estradiol (H3-E2). 
Figure 1

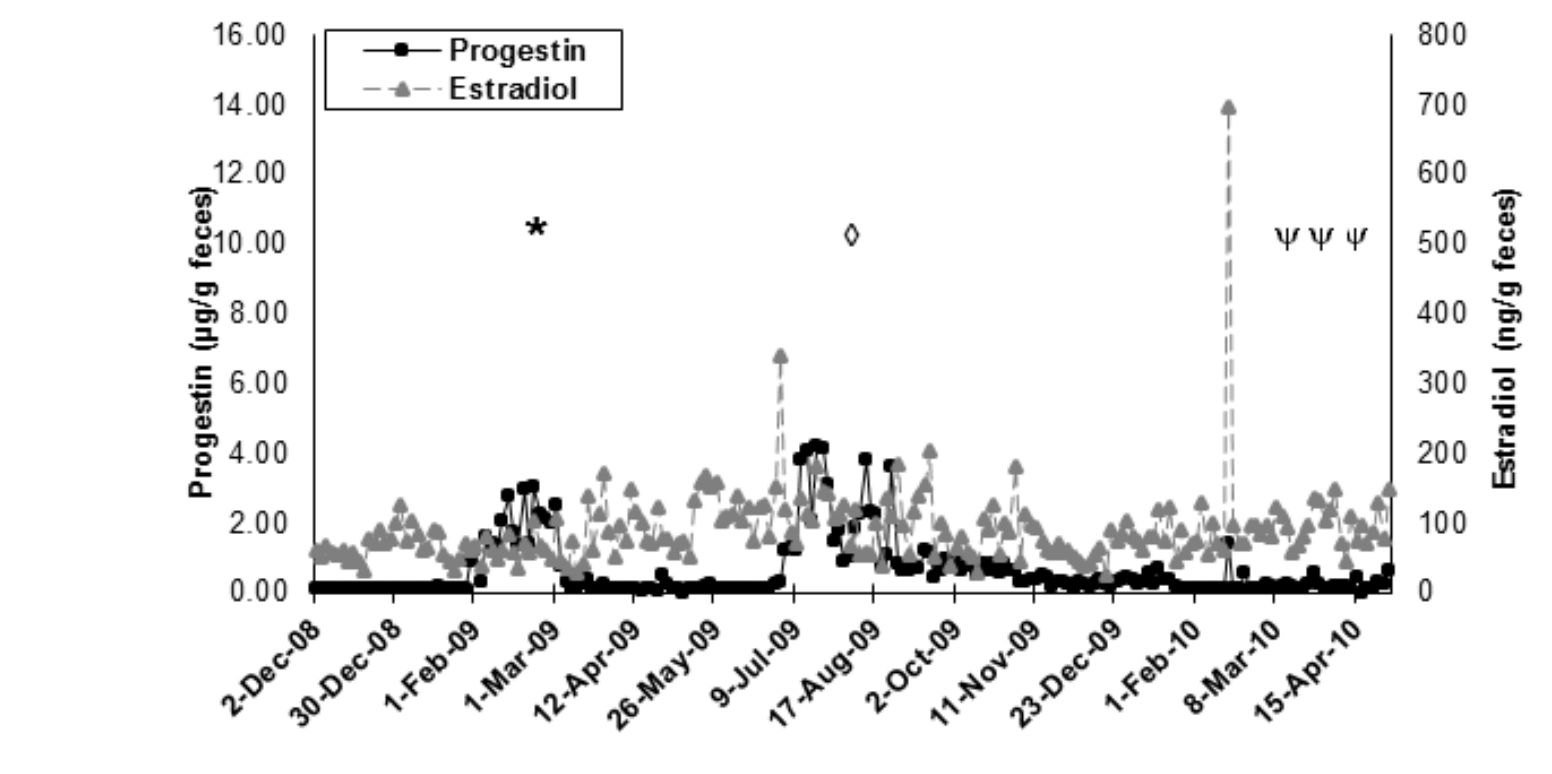

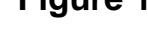

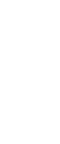

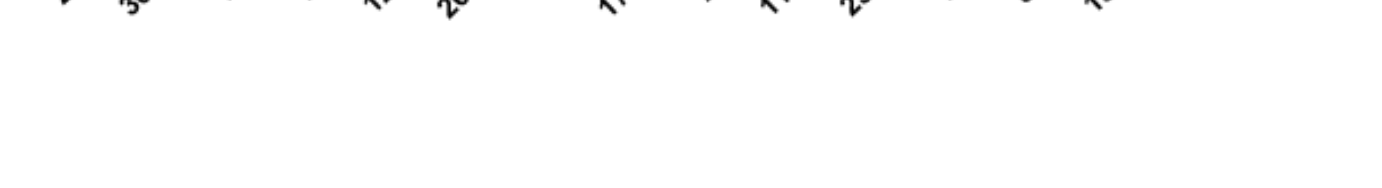
10

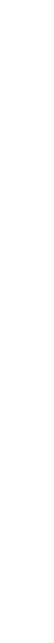

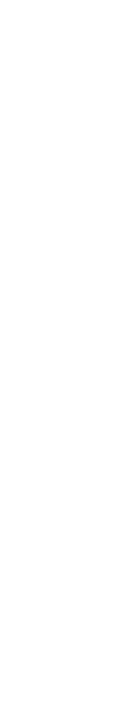


Figure 2

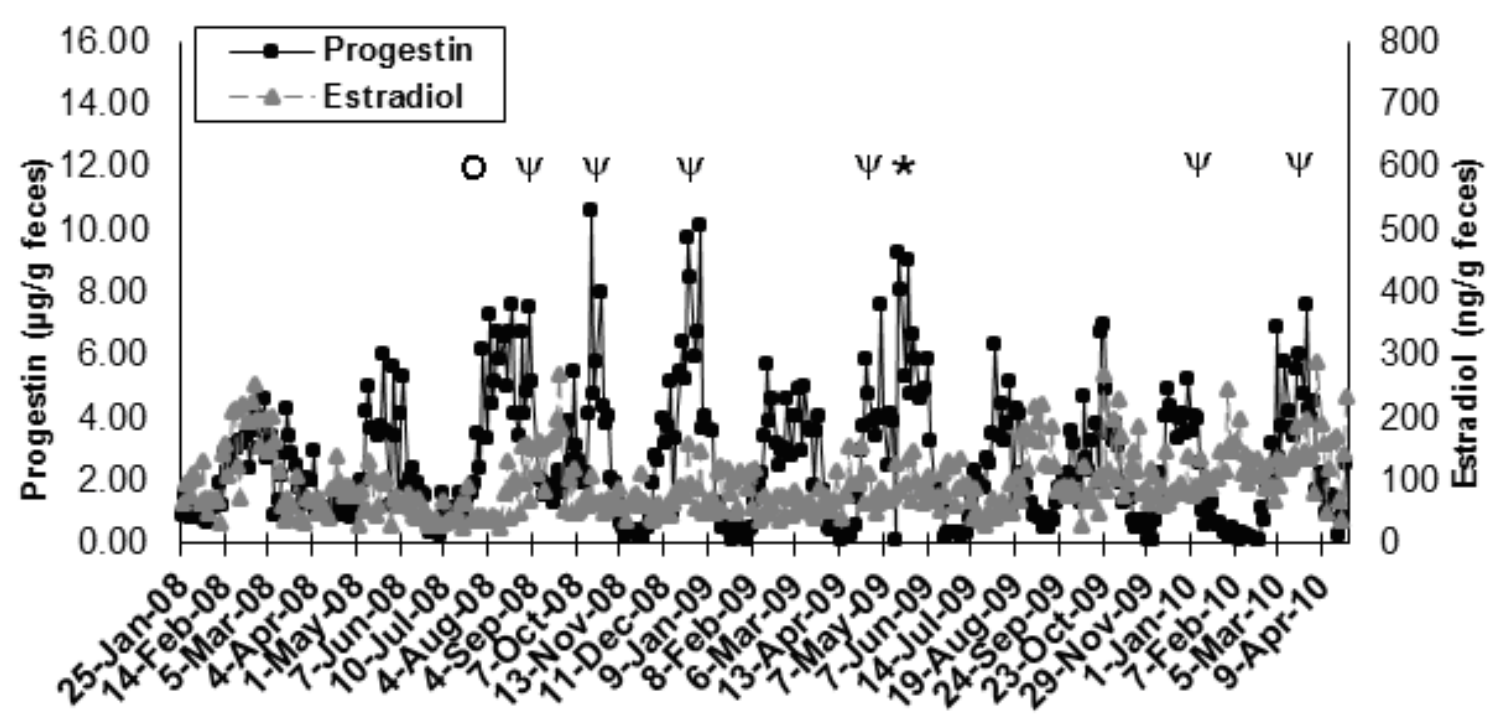


Figure 3

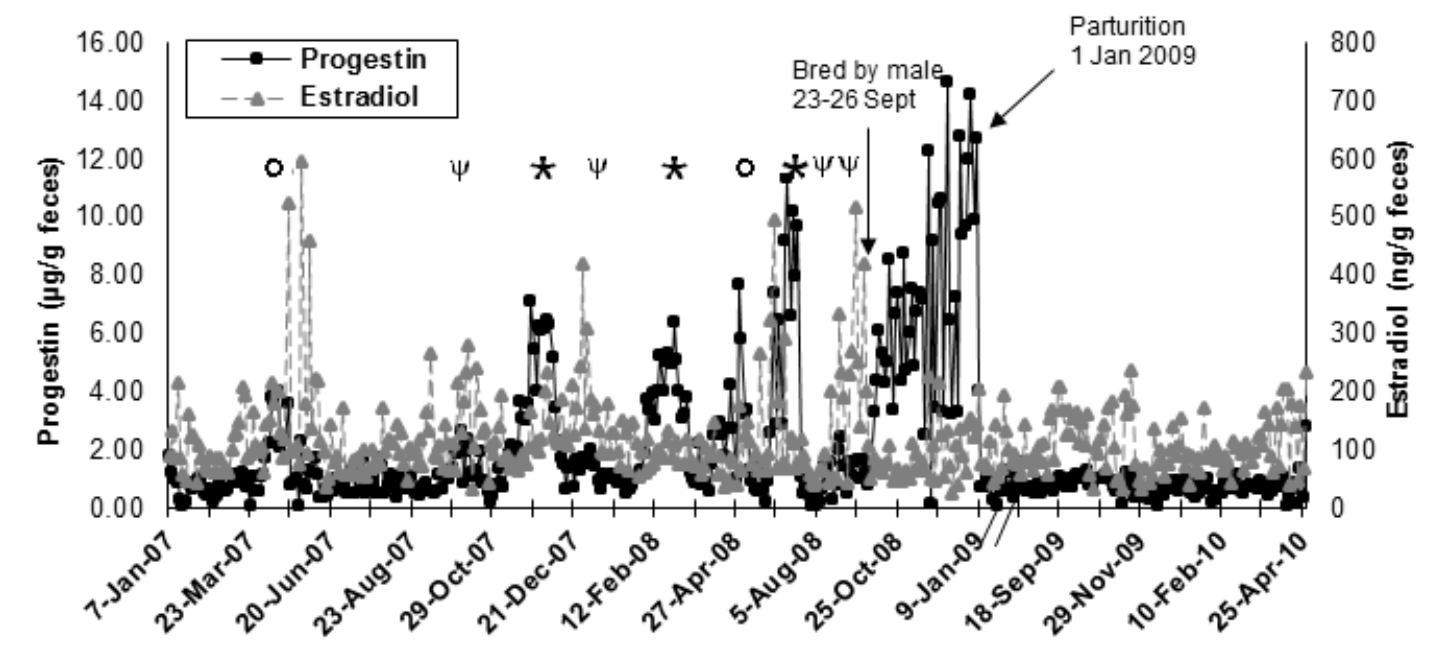


Figure 4

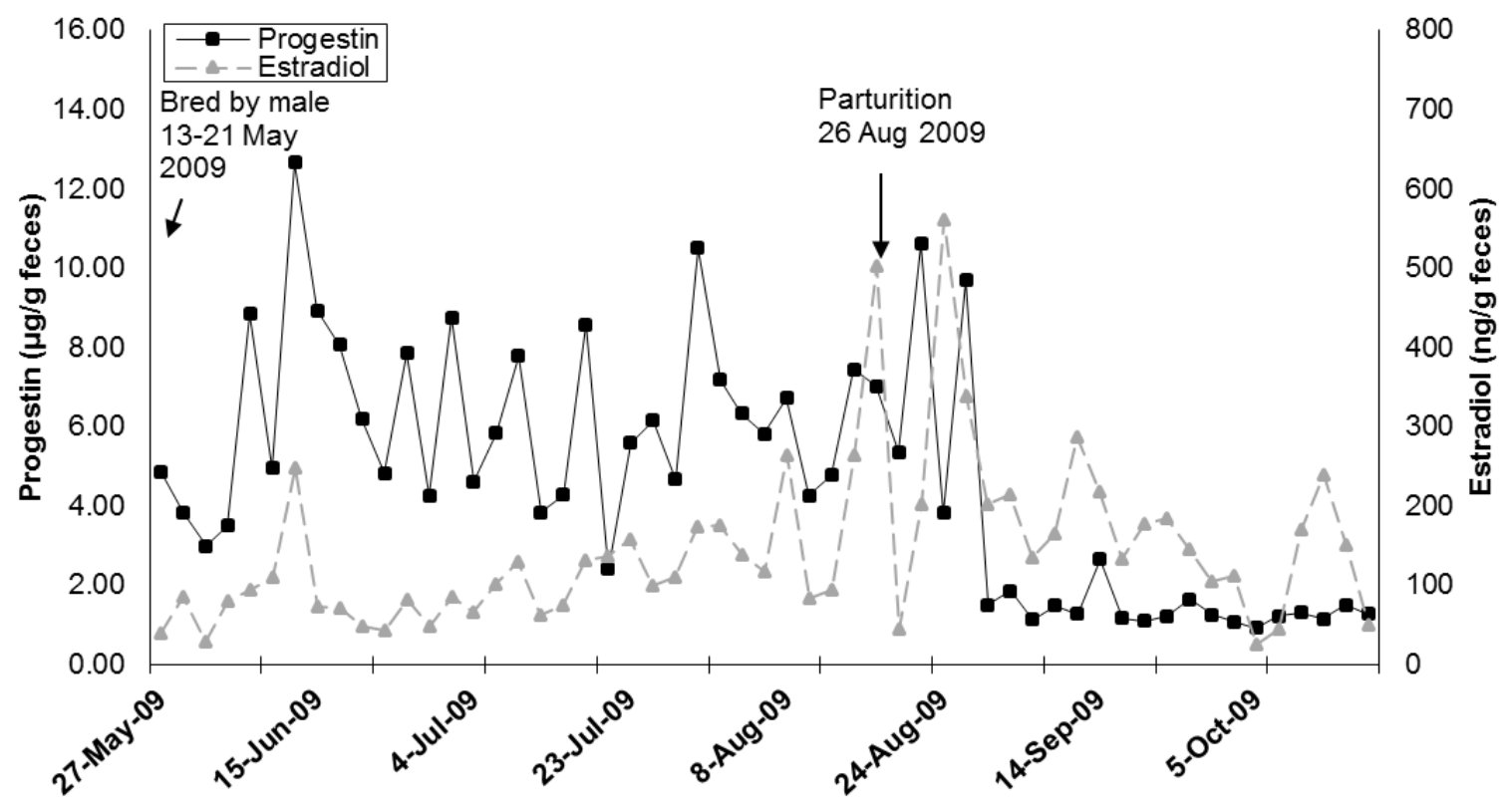


Figure 5

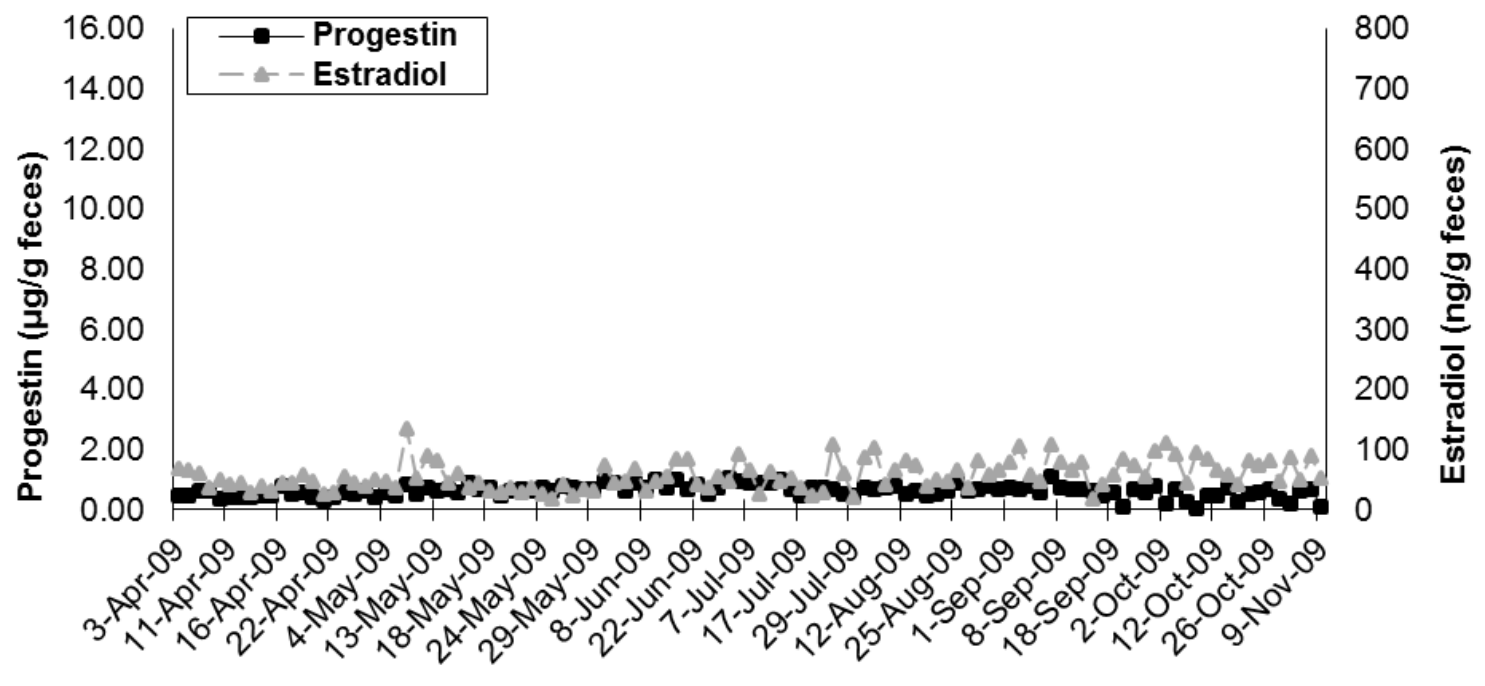


Figure 6

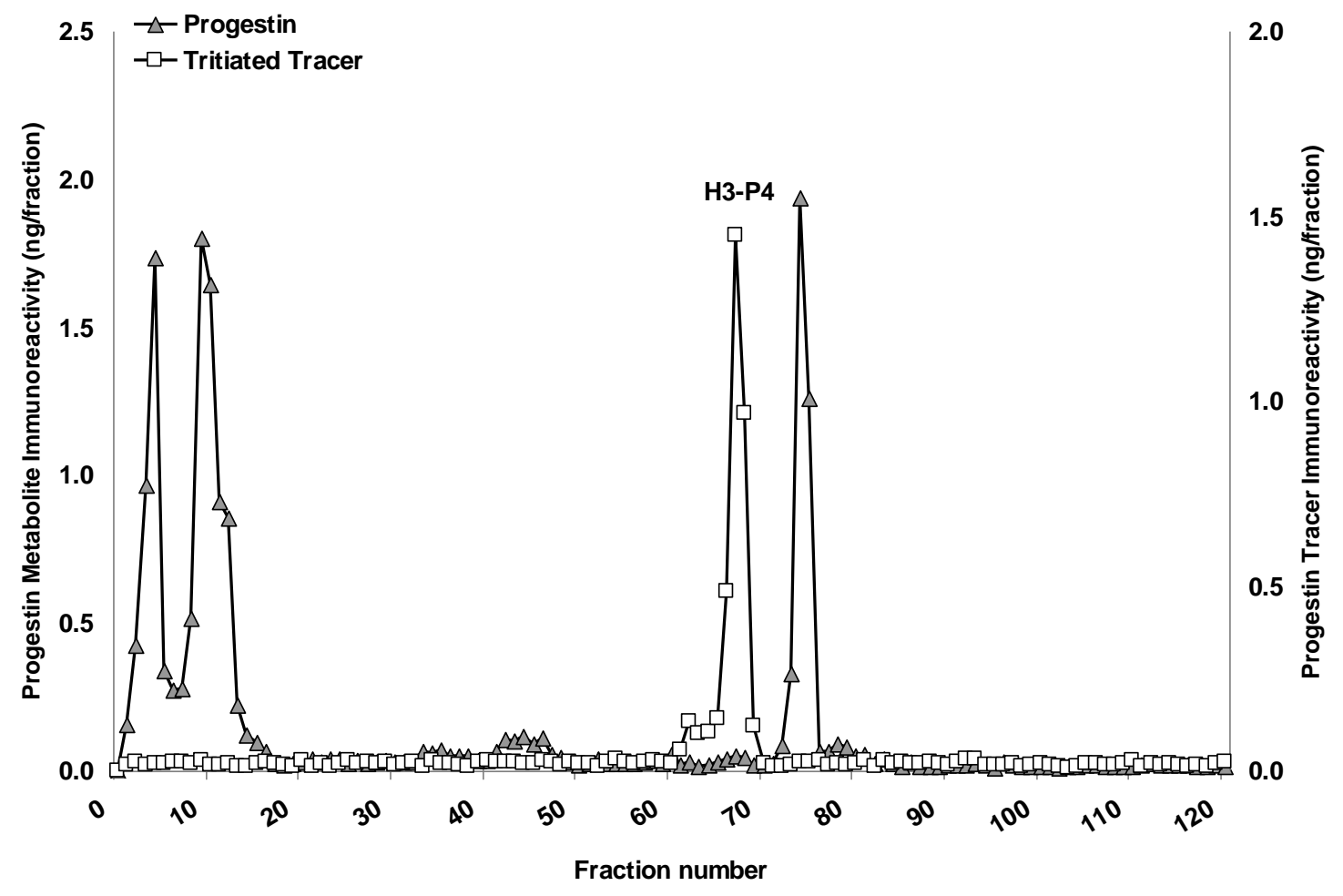


Figure 7

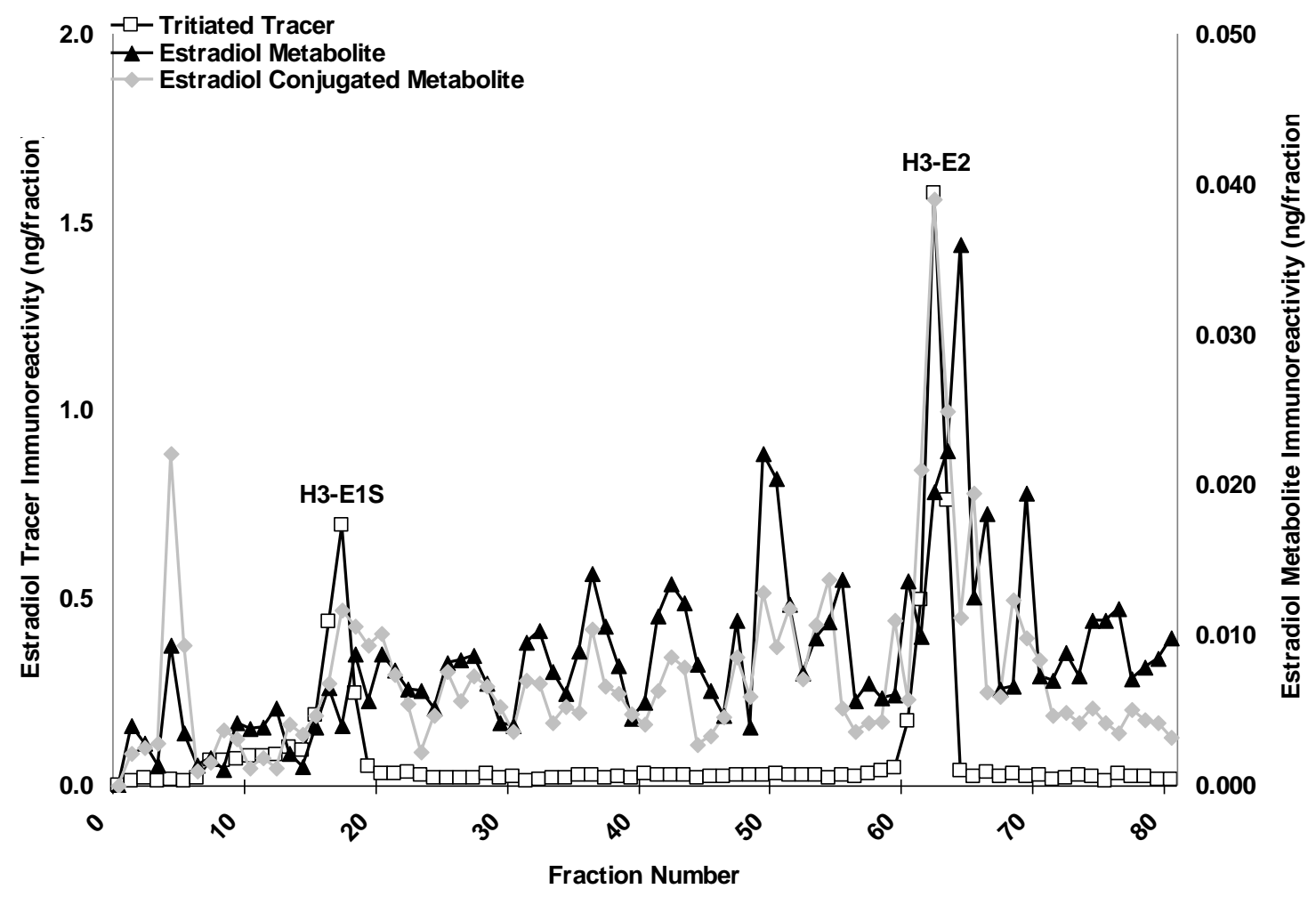

